\title{
Evaluation of Online Teaching Quality of Basic Education Based on Artificial Intelligence
}

\author{
https://doi.org/10.3991/ijet.v15i16.15937 \\ Moyan Li \\ Shantou Polytechnic, Shantou, China \\ Yawen $\mathrm{Su}\left({ }^{\square}\right)$ \\ The Education University of Hong Kong, Hong Kong, China \\ suyawen0209@163.com
}

\begin{abstract}
In the age of the Internet, basic education faces several new challenges: the lack of deep integration of artificial intelligence (AI), and the relatively poor quality of online teaching. To cope with these challenges, this paper designs an evaluation method for online teaching quality of basic education in the context of the AI. Firstly, the application of the AI in basic education was analyzed, and the promoting effect of online teaching on basic education was confirmed. On this basis, the entropy weight method and grey clustering analysis were introduced to evaluate the online teaching quality of basic education. Based on the proposed model, several strategies were proposed to improve the quality of online teaching in basic education. The research results provide a good reference for the application of online teaching and $\mathrm{AI}$ in basic education.
\end{abstract}

Keywords-Teaching quality, online teaching, basic education, evaluation method, artificial intelligence (AI).

\section{Introduction}

Basic education is a very important part of national education, it plays an important role in improving the overall quality of the people, and the implementation of basic education exerts great functions in aspects such as students' knowledge accumulation, learning ability improvement, and the cultivation of learning methods, and thus providing indispensable supports to the cultivation of senior talents in the country [14]. Especially in recent years, with the rapid development of AI technology and the improvement of comprehensive education, many countries attach even greater importance to basic education, and the online teaching mode of basic education has gradually been emphasized [5-8]. In China, online teaching mode of basic education has been carried out not only in provinces with higher economic development level such as Guangdong Province and Zhejiang Province, but also in rural primary schools in mainland areas of China; especially under the influence of the new coronavirus, the successful application of online courses has promoted the in-depth development of the online teaching mode of basic education. 
The implementation of the online teaching mode of basic education not only brings great changes to the teaching concept and methods of basic education, but also makes the process of basic education more intuitive, convenient and effective, and it also gives excellent instructions to the learning of the students, therefore, it has a positive and promotive role in improving the teaching quality of basic education $[9,10]$. To this end, many experts and researchers have conducted a series of research and analysis on the application of online teaching in education, and proposed many constructive strategies and suggestions, so as to provide instructive research results for the development of online teaching of basic education. For example, Cheng and Wang [11] have conducted research on the evaluation of online teaching quality based on Smart Classrooms. Li et al. [12] discussed the development of an online teaching platform for high-quality basic education. Hsu and Wang [13] discussed how to apply the game mechanism and the problems of students to the online mind-exercising game learning system, and use it to enhance students' thinking skills in algorithms. Wang [14] discussed how to use multimedia network technologies to improve the quality of Chinese language teaching in primary schools. Shang [15] studied a classification and evaluation system for online teaching quality based on mobile terminals. Yu [16] analyzed how to use network resources to optimize Chinese language teaching in primary schools and improved the online teaching quality of Chinese language courses in primary schools.

However, considering the different levels of economic development in various countries and regions, there's an imbalance in the allocation of basic education resources, so the application of online teaching in basic education is also very different. At the same time, because experts and researchers have different research perspectives on the application of online teaching in education, this may result in certain limitations in the application range of corresponding research results. To this end, by summarizing and analyzing the existing research materials and drawing on relevant research results, this paper further discusses and analyzes the evaluation method for the online teaching quality of basic education in the context of AI, in the hopes of providing better supports for the in-depth application of online teaching in basic education. The content of this paper includes five parts. The first part is an overview of online teaching of basic education in the context of AI and the quality evaluation research; the second part is an analysis of the current application situation of AI in basic education, and its problems and shortcomings; the third part discusses the promotive effect of online teaching on the quality of basic education; the fourth part establishes an improved model for the quality evaluation of the online teaching of basic education; the fifth parts gives the conclusion of the paper.

\section{Application of AI in Basic Education}

Based on the investigation and analysis of the Chinese language teaching in rural primary and secondary schools in Guangdong province, we can see that, at present, there're shortcomings with the application of AI in basic education. 


\subsection{Insufficient software and hardware support}

On the whole, the application of AI in basic education is not intensive enough; no matter in cities or rural areas, the basic equipment is mostly multimedia classrooms, computer centers or network information centers, etc., the case of the application of $\mathrm{VR}, 3 \mathrm{D}$, and big data is still rare, and the typical form of the application of $\mathrm{AI}$ in basic education is online teaching. At the same time, compared with the conditions in cities, the software and hardware facilities of online teaching of basic education in rural primary schools are much worse; taking the teaching of Chinese language as an example, in case of basic education in cities, common schools generally conduct online teaching using multimedia classrooms and computer centers, and every student has computers, laptops, mobile phones, or other tools that can support online learning, especially during the outbreak of new coronavirus, such online teaching mode has achieved excellent teaching effect. However, some rural primary and secondary schools do not have such hardware equipment, there's no such intelligent classroom in the schools; many students are left-behind children, and they do not have computers, laptops, mobile phones, or other tools that can support online learning; moreover, in some places, there're deficiencies in the application of Internet technology, resulting in that the effect of online teaching hasn't reached the expected goal.

\subsection{Unclear cognition and positioning}

Although AI technology has been developed rapidly and has been widely applied in engineering fields, the application of $\mathrm{AI}$ in basic education is relatively backward and still in its infancy, which makes school administrators, teachers and students ambiguous about its cognition and positioning. At first, from the perspective of cognition, school administrators or teachers do not have professional knowledge about AI or thorough understanding about AI technologies, so they just simply take it as a means for the teaching of basic education. From the perspective of positioning, since $\mathrm{AI}$ is only taken as a means for teaching, during its application, we might only pursue the technical support, while ignoring the ideological cognition. In fact, in terms of the development trend of AI, the development of basic education should take the direction of intelligent education, that is, the teaching concept of basic education must undergo major changes, and it should be very different from the teaching concept of basic education in traditional classrooms.

\subsection{Imperfect faculty team}

Due to the relatively limited education investment in rural primary and secondary schools, their faculty teams are generally weak; compared with the development of primary and secondary schools in urban areas, the development level of rural primary and secondary schools is lagging behind. This situation makes it difficult for these schools to attract excellent young and middle-aged teachers to teach in rural areas; moreover, due to the shortage in educational resources, it's also hard for these schools to keep the teaching talents, thus resulting in severe outflow of talents. At the same 
time, due to the limited manpower, material and financial resources investments, the schools can hardly cultivate excellent teachers that have typical teaching outcomes, and the training for famous teachers is also very lacking. Therefore, the construction of school faculty teams doesn't have the characteristics of talent echelon, and the sustainability of education development has been greatly affected. Especially under the conditions of the rapid development of AI, due to the weakness in the faculty team, the teachers only have a very limited understanding of the computer technology, network technology and information technology, so it's of great difficulty to construct a faculty team with good qualities in AI for the basic education.

\subsection{Simple application form}

At present, the application of AI in education is mainly reflected in aspects such as computer technology, network technology, information technology and multimedia technology. The comprehensive application of these technologies provides a technical support for the implementation of the online teaching of basic education, and a few online teaching platforms have emerged. Right now, although there are many platforms for online teaching, such as rain classroom, cloud classroom, MOOC, flipped classroom, and Dingding classroom, etc., the application forms of these online teaching platforms are often relatively simple and not as varied; they just display the courseware or the teachers' teaching videos, while neglecting the interaction, communication and feedback of online teaching in basic education. There're large differences between basic education and higher education. Because the students of basic education are young children, they generally do not have good ability in self-learning and self-discipline; and this requires that, during the implementation process of the online teaching of basic education, teachers and students should keep good communication and interaction, it should be able to effectively urge students to complete their homework, and feed back to teachers in a timely manner, so as to reflect the application effect of online teaching.

\subsection{Deficient supervision and assessment mechanism}

Since the application of intelligent technologies in basic education is not deep enough, its support to basic education is relatively weak; due the limited investment in the AI-based basic education, the implementation of AI-based basic education has not been valued very much, resulting in that the school administrators often ignore the effective supervision and assessment of the implementation of intelligent basic education, and it hasn't formed a set of effective supervision and assessment mechanism yet. This makes the teachers have a wrong understanding that, whether to use intelligent teaching technology or not is the same, and whether to use good intelligent teaching technology or bad intelligent teaching technology is also the same. Over time, this will cause some teachers to pay little attention to the implementation of AIbased basic education, and they usually take the traditional teaching methods and modes during the course lecturing process, in such case, AI-based basic education becomes mere a formality and hasn't been applied effectively. Therefore, it is neces- 
sary to improve the supervision and assessment mechanism of the AI-based basic education.

\section{Promotive Effect of Online Teaching on the Teaching Quality of Basic Education}

As a typical application form of AI in basic education, the author believes that online teaching has a great role in improving the teaching quality of basic education, which is mainly reflected in the following aspects:

\subsection{More advanced teaching concept for basic education}

The implementation of the online teaching mode makes the basic education more contemporary and can better reflect the intelligent characteristics of basic education, enabling the basic education to proceed in the direction of intelligent education. Through the integration of intelligent technologies, under the human-oriented education concept, students' knowledge, abilities and qualities could be better expanded, so that the students could develop and improve themselves in aspects of morals, intelligence, physical fitness, beauty, and labor more comprehensively and perfectly, and they could meet the requirements of the development of times.

\subsection{Richer teaching methods for basic education}

Compared with the traditional classroom teaching method, the online teaching of basic education makes use of the network technology, computer technology, information technology, and big data technology, which makes the knowledge transfer tools, media and equipment of basic education more diverse, and can meet the requirements and demands of different teaching links. Taking the elementary school Chinese language teaching as an example, this course focuses more on the aspects of students' listening, speaking, reading, and writing; and the audio and video technologies, speech recognition technology, and VR technology provide technical supports for the knowledge transfer of these aspects, making it easier for students to absorb and digest the Chinese language knowledge.

\subsection{Highly shared teaching content of basic education}

Due to the introduction of intelligent technology, the teaching content of basic education has more preservation forms and types, according to the different forms and types of the teaching content of basic education, corresponding database, knowledge banks or teaching case libraries could be constructed, so as to achieve effective collection and storage of the teaching content of basic education. Then, by setting key words or key identifiers, we can query and categorize the teaching content of basic education, so that it is easier to obtain teaching content that meets the teaching or 
learning goals, especially under the support of network technology and information technology, the teaching content of basic education could be highly shared.

\subsection{More diversified teaching methods of basic education}

With the support of intelligent technology, the teaching methods of basic education become more abundant; with the continuous accumulation of the teaching content of basic education, the teaching content of various forms and types, such as courseware, audio, video, animation, and documents, can better meet the requirements of modern basic education, and they are more conductive to the implementation of teaching methods, that is, according to the integration of teaching methods and teaching content, the lecturing method, exercise method, discussion method, presentation method and task drive method of online teaching could be applied reasonably and comprehensively, so as to achieve better learning effect of basic education.

\subsection{More controllable teaching progress of basic education}

From the perspective of teachers' teaching, the implementation of online teaching of basic education allows teachers to comprehensively formulate the syllabus, teaching plans, teaching tasks and teaching content; moreover, under the support of intelligent technology, teachers can more easily collect teaching information and teaching materials related to the courses, especially information feedback related to students' learning, and it's easier for course teachers to know the learning status of students, so that they can adjust the teaching tasks and perfect the teaching schemes an plans in a targeted manner, thereby adaptively adjusting the teaching progress during the course teaching process, and making the teaching progress of basic education more flexible.

\subsection{Higher teaching efficiency of basic education}

The implementation of online teaching of basic education not only enables the teaching content to be displayed more intuitively and formally to students, but also makes the lecturing faster and easier; in particular, the online teaching of basic education provides good conditions for the interaction and communication of teachers and students, so that they can exchange in a timely manner, which is more conducive for students to absorb and digest the knowledge points, key content and difficult content taught by the teachers; moreover, online teaching also reduces the delay of learning and communication between students and teachers under the traditional teaching mode, and improves the teaching efficiency of course teachers of basic education. 


\section{A Quality Evaluation Model for the Online Teaching of Basic Education}

\subsection{The quality evaluation system for online teaching of basic education}

It can be seen from the implementation process of the online teaching of basic education that, the online teaching of basic education includes three parts: course teachers' online teaching, online teaching intermediary, and students' online learning; therefore, the teaching quality of online teaching of basic education is affected by factors in the three aspects. For this reason, in order to analyze the teaching quality of basic education from an overall perspective, the author constructs a corresponding quality evaluation system for online teaching quality from three aspects.

Course teachers' online teaching: The perspective of course teachers' online teaching mainly investigates the course teachers' professional literacy and teaching effect in the online teaching environment. It's mainly manifested in aspects of: online teaching platform operation ability, the content lecturing of online teaching (including the design, organization and lecturing of the teaching content), the online teaching attitude, the online teaching method application, the teaching manner, the online teaching task completion, the online teaching scheme and courseware preparation and planning, the online classroom effect, the online teaching interaction and communication, the student homework correction and instruction ability, and the online teaching information feedback ability, etc.

Online learning platform construction: The perspective of online learning platform construction mainly examines the performance of the online learning platform of basic education, generally, we need to consider the following aspects:

1. The compatibility of the online learning platform and whether it can adapt to different operating systems or operating software

2. The stability of the online learning platform, and try to avoid system crashes during online learning as much as possible

3. The sharing feature of the online learning platform, so as to facilitate the capture and conversion of the learning content

4. The scalability of the online learning platform, especially the addition and upgrade of some new-type teaching or learning function modules

5. The portability of the online learning platform, and could achieve the reconfigurability of key components

6. The operability of the online learning platform, that is, it could be more conducive to the use of teachers and students, and to achieve intelligent operation.

Students' online learning: The perspective of students' online learning mainly examines students' online learning processes and effect in the environment of online teaching of basic education; it's mainly reflected in the aspects of: students' online learning concentration, online learning participation, online learning absorption capacity, homework completion of online learning, information feedback ability of online learning, and online learning effect, etc. In terms of online learning effect, 
many forms such as classroom tests, unit tests, mid-term tests, final tests, and homework results could be taken to assess students' online learning effect.

\subsection{Processing of the weights of quality evaluation indicators for the online teaching of basic education}

As can be seen from the quality evaluation system for the online teaching of basic education, there are quite a few indicators for the quality of online teaching and there're multiple evaluation levels, and the evaluation indicators of different levels generally have different importance to the overall evaluation results, to this end, it's necessary to process the weights of the quality evaluation indicators of the online teaching of basic education. This paper uses the entropy weight method [17-21] to process the weights of the quality evaluation indicators of online teaching. According to the information theory, entropy is a standard for measuring the uncertainty of the system. The greater the uncertainty of the system, the more information the system contains and the greater the corresponding entropy value. Conversely, the smaller the uncertainty of the system, the less information the system contains, and the smaller the corresponding entropy value. To this end, the entropy value can be used to judge the dispersion degree of the quality evaluation indicators of online teaching, the greater the dispersion degree, the greater the impact of the quality evaluation indicators on the comprehensive evaluation structure, and the greater the corresponding weight.

Suppose that $n$ evaluation experts are invited to give initial scores for $m$ evaluation indicators; wherein xij represents the score value of the $\mathrm{j}$-th evaluation indicator given by the i-th evaluation expert; since different indicators may have different score dimensions, it needs to standardize the evaluation indicators, if an indicator is a performance indicator, then after standardization, the score value rij can be expressed as:

$$
r_{i j}=\frac{x_{i j}-\min _{1 \leq i \leq n}\left(x_{i j}\right)}{\max _{1 \leq i \leq n}\left(x_{i j}\right)-\min _{1 \leq i \leq n}\left(x_{i j}\right)}
$$

This indicator is a cost indicator, then after standardization, the score value rij can be expressed as:

$$
r_{i j}=\frac{\max _{1 \leq i \leq n}\left(x_{i j}\right)-x_{i j}}{\max _{1 \leq i \leq n}\left(x_{i j}\right)-\min _{1 \leq i \leq n}\left(x_{i j}\right)}
$$

Then the entropy value ej of the $\mathrm{j}$-th evaluation indicator can be expressed as: 


$$
e_{j}=-\frac{1}{\ln (n)} \sum_{i=1}^{n}\left(\frac{r_{i j}}{\sum_{i=1}^{n} r_{i j}} * \ln \left(\frac{r_{i j}}{\sum_{i=1}^{n} r_{i j}}\right)\right)
$$

In particular, if $\frac{r_{i j}}{\sum_{i=1}^{n} r_{i j}}=0$, then:

$$
\lim _{\substack{r_{i j} \\ \sum_{i=1}^{n} r_{i j}}}\left(\frac{r_{i j}}{\sum_{i=1}^{n} r_{i j}} * \ln \left(\frac{r_{i j}}{\sum_{i=1}^{n} r_{i j}}\right)\right)=0
$$

From this, the weight wj of the $\mathrm{j}$-th evaluation indicator can be obtained as:

$$
w_{j}=\frac{1-e_{j}}{\sum_{j=1}^{m}\left(1-e_{j}\right)}
$$

\subsection{Implementation of the quality evaluation model for the online teaching of basic education}

In order to effectively distinguish the teaching quality categories or grades of different evaluation objects, based on the application of gray theory [22-26], this paper adopts the gray clustering analysis method [22-26] to conduct analysis on it. By consulting field experts, scholars and related managers, in this paper, the gray categories of the online teaching quality evaluation of basic education are divided into three forms.

The gray clustering analysis function corresponding to the first form is denoted as $\psi \mathrm{A}(\mathrm{u})$, and its function graph structure is shown in Figure 1. 


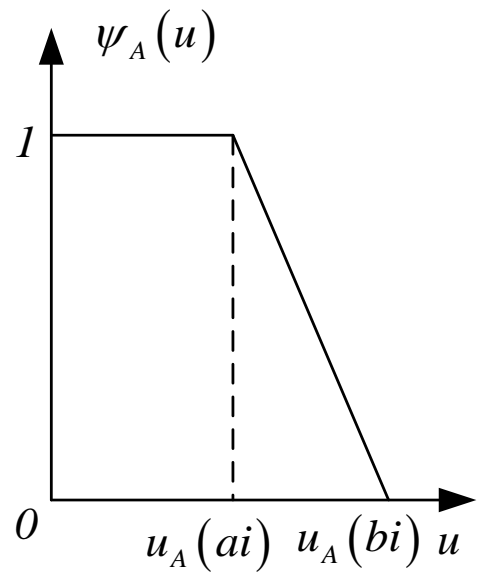

Fig. 1. Structure of gray clustering analysis function $\psi_{A}(u)$

If the standardized value of the $\mathrm{i}$-th evaluation object with respect to the $\mathrm{j}$-th evaluation indicator is uij, then the gray clustering analysis function is denoted as $\psi_{A}^{i}(u)$, and the corresponding calculation model is:

$$
\psi_{A}^{i}(u)= \begin{cases}0 & u_{i j} \geq u_{A}(b i) \\ \frac{u_{A}(b i)-u_{i j}}{u_{A}(b i)-u_{A}(a i)} & u_{A}(a i) \leq u_{i j} \leq u_{A}(b i) \\ 1 & 0 \leq u_{i j} \leq u_{A}(a i)\end{cases}
$$

The gray clustering analysis function corresponding to the second form is denoted as $\psi \mathrm{B}(\mathrm{u})$, and its function graph structure is shown in Figure 2.

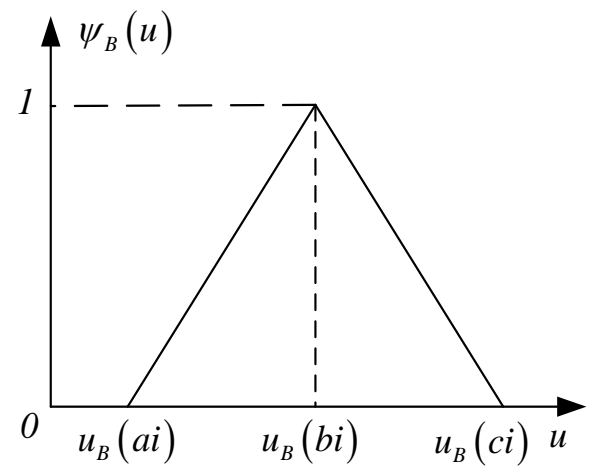

Fig. 2. Structure of gray clustering analysis function $\psi_{B}(u)$ 
If the standardized value of the $\mathrm{i}$-th evaluation object with respect to the $\mathrm{j}$-th evaluation indicator is uij, the gray clustering analysis function is denoted as $\psi_{B}^{i}(u)$, the corresponding calculation model is:

$$
\psi_{B}^{i}(u)= \begin{cases}0 & u_{i j} \leq u_{B}(a i) \text { or } u_{i j} \geq u_{B}(c i) \\ \frac{u_{i j}-u_{B}(a i)}{u_{B}(b i)-u_{B}(a i)} & u_{B}(a i) \leq u_{i j} \leq u_{B}(b i) \\ \frac{u_{B}(c i)-u_{i j}}{u_{B}(c i)-u_{B}(b i)} & u_{B}(b i) \leq u_{i j} \leq u_{B}(c i) \\ 1 & u_{i j}=u_{B}(b i)\end{cases}
$$

The gray clustering analysis function corresponding to the third form is denoted as $\psi \mathrm{C}(\mathrm{u})$, and its function graph structure is shown in Figure 3.

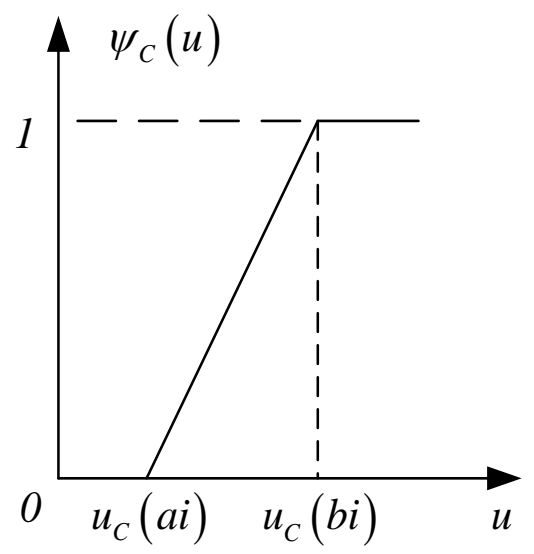

Fig. 3. Structure of the gray clustering analysis function $\psi c(u)$

If the standardized value of the $\mathrm{i}$-th evaluation object with respect to the $\mathrm{j}$-th evaluation indicator is uij, the gray clustering analysis function is denoted as $\psi_{C}^{i}(u)$, the corresponding calculation model is:

$$
\psi_{C}^{i}(u)= \begin{cases}1 & u_{i j} \geq u_{C}(b i) \\ \frac{u_{i j}-u_{C}(a i)}{u_{C}(b i)-u_{C}(a i)} & u_{C}(a i) \leq u_{i j} \leq u_{C}(b i) \\ 0 & u_{i j} \leq u_{C}(a i)\end{cases}
$$


Considering the weight $w j$ of the $\mathrm{j}$-th evaluation indicator, then the weighted gray correlation $\sigma \mathrm{k}(\mathrm{i})$ of the $\mathrm{i}$-th evaluation object and the k-th gray category is:

$$
\sigma_{k}(i)=\sum_{j=1}^{n}\left(w_{j} * \psi_{k}^{i}(u)\right)
$$

Therefore, according to the size of the weighted gray correlation degree $\sigma \mathrm{k}(\mathrm{i})$, the category of the evaluation object of online teaching quality could be determined. If there are multiple evaluation objects that need to be analyzed during the evaluation process, above analysis steps could be adopted repeatedly to determine the category of the evaluation object of online teaching quality.

\subsection{Strategies and suggestions for improving the online teaching quality of basic education}

From the implementation process of online teaching of basic education, we can see that, if the evaluation object's grey category is a low-level one, it indicates that there are weak links in the teaching quality, therefore, the online teaching quality needs to be improved. In order to effectively improve the online teaching quality of basic education, the author believes that we need to analyze and improve the specific weak links in online teaching based on the evaluation results; meanwhile, combining with the shortcomings in the online teaching of basic education and the analysis of the promotive role of online teaching in basic education quality given by the author, this study believes that we can take some basic measures or means to ensure the improvement of the online teaching quality of basic education; for example, by improving the basic construction ability of online teaching of basic education, improving the comprehensive literacy of the professional teachers of online teaching, enhancing the shareability of the teaching resources of online teaching, increasing the investment in online teaching, and perfecting the management system of online teaching, the online teaching quality of basic education could be better guaranteed.

\section{Conclusion}

This paper studied a quality evaluation method for online teaching of basic education based on AI, it analyzed the application status of AI in basic education, and pointed out that online teaching has a good promotive role in enhancing the online teaching quality of basic education. In order to realize effective evaluation and analysis on the online teaching quality of basic education, this paper constructed an improved model to evaluate the online teaching quality of basic education, and gave detailed discussion on the online teaching quality evaluation system, the processing of the weights of evaluation indicators, the realization of evaluation algorithm, and strategies for improving the online teaching quality of basic education. The study is an important theoretical innovation and has engineering application value. At the same 
time, it also has a good reference significance for the processing of education and teaching quality of other types with similar characteristics.

\section{Acknowledgement}

This work is supported by Young Innovative Talent Project of Guangdong Colleges and Universities 2019 (Composition of Educational Technical Capability of Rural Primary School Teachers in the Age of Artificial Intelligence) (No. 2019GWQNCX137).

\section{$7 \quad$ References}

[1] Fauth, B., Decristan, J., Decker, A. T., Büttner, G., Hardy, I., Klieme, E., Kunter, M. (2019). The effects of teacher competence on student outcomes in elementary science education: The mediating role of teaching quality. Teaching and Teacher Education, 86, 102882. https://doi.org/10.1016/j.tate.2019.1028824

[2] Bessho, S., Noguchi, H., Kawamura, A., Tanaka, R., Ushijima, K. (2019). Evaluating remedial education in elementary schools: Administrative data from a municipality in Japan. Japan and the World Economy, 50, 36-46. https://doi.org/10.1016/j.japwor.2019.04.003

[3] Yamamoto, T., Matsumoto, Y., Bernard, M. E. (2017). Effects of the cognitive-behavioral you can do it! Education program on the resilience of Japanese elementary school students: a preliminary investigation. International Journal of Educational Research, 86, 50-58. http ://doi.org/10.1016/j.ijer.2017.08.006

[4] González-Treviño, I. M., Núñez-Rocha, G. M., Valencia-Hernández, J. M., ArronaPalacios, A. (2020). Assessment of multiple intelligences in elementary school students in Mexico: An exploratory study. Heliyon, 6(4), e03777. https://doi.org/10.1016/j.heliyon.20 20.e03777

[5] Xiao, R., Xiao, H.M., Shang, J.J. (2020). Artificial intelligence and educational reform: Prospects, difficulties, and strategies. China Educational Technology, (4), 75-86.

[6] Xiong, M., Wang, M. (2019). The characteristics, achievements and prospects of China's primary education and teaching reform since the reform and opening up 40 years. Journal of Sichuan Normal University (Social Sciences Edition), 46(1), 78-85. https://doi.org/10.1 3734/j.cnki.1000-5315.2019.01.010

[7] Sukhbaatar, O., Usagawa, T., Choimaa, L. (2019). An artificial neural network based early prediction of failure-prone students in blended learning course, International Journal of Emerging Technologies in Learning, 14: 77-92. https://doi.org/10.3991/ijet.v14i19.10366

[8] Kim, C., Kim, D., Yuan, J., Hill, R. B., Doshi, P., Thai, C. N. (2015). Robotics to promote elementary education pre-service teachers' STEM engagement, learning, and teaching. Computers \& Education, 91, 14-31. https://doi.org/10.1016/j.compedu.2015.08.005

[9] Qi, H.Y., Han, L.P. (2020). How to use the Internet to improve the quality of rural primary education and teaching. Western China Quality Education, (6), 127-128. https://doi.org/10. 16681/j.cnki.wcqe. 202006065

[10] Jiang, F.Y. (2019). Challenges and changes of elementary education in the era of "Internet +". Education Modernization, (49), 90-91. https://doi.org/10.16541/j.cnki.2095-8420.2019. $\underline{49.029}$

[11] Cheng, M., Wang, X.Y. (2020). Research on the quality evaluation of network teaching in the smart classroom. Journal of Fujian Computer, 36(2), 120-121. https://doi.org/10.16707/ j.cnki.fjpc.2020.02.035 
[12] Li, L.Y., Hu, H., Hu, S., Cai, Y.X., Cai, Z.Q. (2016). Research oriented to quality basic education network teaching platform. Computer \& Telecommunication, (5), 23-24, 39. https://doi.org/10.15966/j.cnki.dnydx.2016.05.007

[13] Hsu, C.C., Wang, T.I. (2018). Applying game mechanics and student-generated questions to an online puzzle-based game learning system to promote algorithmic thinking skills. Computers \& Education, 121, 73-88. https://doi.org/10.1016/j.compedu.2018.02.002

[14] Wang, F.X. (2019). The application of multimedia network technology in primary school Chinese teaching. Read and Write Periodical, 16(8), 146. http://dx.doi.org/10.16071/j.cnki. cn51-1650/g4.2019.08.129

[15] Shang, Y.F. (2019). Classification evaluation system of network teaching quality based on mobile terminal. Journal of Anyang Institute of Technology, 18(6), 56-59. https://doi.org/ 10.19329/j.cnki.1673-2928.2019.06.014

[16] Yu, Z.G. (2020). Using network resources to optimize primary school Chinese teaching. Learning Weekly, 7, 111-112. https://doi.org/10.16657/j.cnki.issn1673-9132.2020.07.055

[17] Delgado, A., Romero, I. (2016). Environmental conflict analysis using an integrated grey clustering and entropy-weight method: A case study of a mining project in Peru. Environmental Modelling \& Software, 77, 108-121. https://doi.org/10.1016/j.envsoft.2015.12.011

[18] Chukwumaobi, O., Akinlabi, E. T., Njoku, H. O. (2020). Selection of phase change material for Improved performance of Trombe wall systems using the entropy weight and TOPSIS methodology. Energy and Buildings, 217, 1-10. https://doi.org/10.1016/j.enbuild. 2020.109967

[19] Davoudabadi, R., Mousavi, S. M., Sharifi, E. (2020). An integrated weighting and ranking model based on entropy, DEA and PCA considering two aggregation approaches for resilient supplier selection problem. Journal of Computational Science, 40, 1-12. https://doi.org/ 10.1016/j.jocs.2019.101074

[20] Benson, D. A., Pankavich, S., Schmidt, M. J., Sole-Mari, G. (2020). Entropy: 1) The former trouble with particle-tracking simulation, and 2) A measure of computational information penalty. Advances in Water Resources, 137, 103509. https://doi.org/10.1016/j.adv watres.2020.103509

[21] Cavallaro, F., Zavadskas, E. K., Streimikiene, D., Mardani, A. (2019). Assessment of concentrated solar power (CSP) technologies based on a modified intuitionistic fuzzy topsis and trigonometric entropy weights. Technological Forecasting and Social Change, 140, 258-270. https://doi.org/10.1016/j.techfore.2018.12.009

[22] Bezuglov, A., Comert, G. (2016). Short-term freeway traffic parameter prediction: Application of grey system theory models. Expert Systems with Applications, 62, 284-292. https ://doi.org/10.1016/j.eswa.2016.06.032

[23] Javed, S. A., Mahmoudi, A., Khan, A. M., Javed, S., Liu, S. (2018). A critical review: shape optimization of welded plate heat exchangers based on grey correlation theory. Applied Thermal Engineering, 144, 593-599. https://doi.org/10.1016/j.applthermaleng.2018.0 $\underline{8.086}$

[24] Karakoç, Ö., Es, H. A., Fırat, S. Ü. (2019). Evaluation of the development level of provinces by grey cluster analysis. Procedia Computer Science, 158, 135-144. https://doi.org/ 10.1016/j.procs.2019.09.036

[25] Temino-Boes, R., Romero-Lopez, R., Ibarra-Zavaleta, S. P., Romero, I. (2020). Using grey clustering to evaluate nitrogen pollution in estuaries with limited data. Science of The Total Environment, 722, 1-12. https://doi.org/10.1016/j.scitotenv.2020.137964

[26] Rajesh, R. (2018). Measuring the barriers to resilience in manufacturing supply chains using Grey Clustering and VIKOR approaches. Measurement, 126, 259-273. https://doi.org/ $\underline{10.1016 / j . m e a s u r e m e n t .2018 .05 .043 . ~}$ 


\section{Authors}

Moyan Li was born in Shantou, China in 1986. He is a doctoral student at The Education University of Hong Kong, and works at Shantou Polytechnic, China (galaxyli@foxmail.com). His research interest includes E-learning, second language acquisition.

Yawen Su was born in Xiamen, China in 1988. She is a doctoral student at The Education University of Hong Kong. (suyawen 0209@163.com). Her research interest includes Chinese education, practical teaching.

Article submitted 2020-06-12. Resubmitted 2020-07-19. Final acceptance 2020-07-23. Final version published as submitted by the authors. 